CLINICAL STUDY

\title{
Longitudinal growth, sexual maturation and final height in patients with congenital hypothyroidism detected by neonatal screening
}

\author{
Mariacarolina Salerno, Maria Micillo, Salvatore Di Maio, Donatella Capalbo, Pasqualina Ferri, Teresa Lettiero and \\ Alfred Tenore ${ }^{1}$ \\ Department of Pediatrics, University of Naples Federico II and ${ }^{1}$ Chair of Pediatrics, DPMSC, University of Udine, Italy \\ (Correspondence should be addressed to Mariacarolina Salerno, Department of Pediatrics, University of Naples Federico II, Via S. Pansini 5, \\ 80131 Naples, Italy; Email: salerno@unina.it)
}

\begin{abstract}
Objective: To evaluate longitudinal growth, pubertal development and final height in patients with congenital hypothyroidism $(\mathrm{CH})$ detected by a neonatal screening programme, and to identify factors potentially affecting growth outcome.

Patients: Fifty-five patients (41 females) detected by neonatal screening and followed longitudinally from the time of diagnosis and treatment ( $25 \pm 5$ days) up to the age of $17 \pm 0.5$ years were evaluated retrospectively.

Results: Pubertal development began and progressed normally in both males and females. In boys, a testicular volume of $4 \mathrm{ml}$ was reached at 11.3 \pm 1.0 years. In girls breast enlargement (B2) occurred at a mean age of $10.3 \pm 1.2$ years and the mean age of menarche was $12.5 \pm 1.2$ years. The onset and the progression of puberty were independent of the aetiology, the severity of $\mathrm{CH}$ and the timing of the beginning of treatment. Girls treated with an initial amount of L-thyroxine $\left(\mathrm{L}-\mathrm{T}_{4}\right)$ greater than $8 \mu \mathrm{g} / \mathrm{kg}$ per day showed an earlier onset of puberty (B2 9.4 \pm 0.9 years; menarche $11.5 \pm 0.8$ years) compared with girls treated with a lower initial dose of $\mathrm{L}-\mathrm{T}_{4}$ (B2 10.5 \pm 1.2 years; menarche $12.6 \pm 1.2$ years; $P<0.02)$. However, both groups attained a similar final height $(-0.1 \pm 1.0$ SDS and $0.4 \pm 1.0$ SDS, respectively), which in both cases was above the target height $(P=0.03)$. All the patients in the study attained a mean final height $(0.1 \pm 1.1$ SDS $)$ within the normal range for the reference population and above the target height $(-0.9 \pm 0.9$ SDS, $P<0.0001)$. No significant relationship was found between final height and severity of $\mathrm{CH}$ at diagnosis, initial $\mathrm{L}_{-} \mathrm{T}_{4}$ dosage or aetiology of the defect. Patients with ectopic gland, thyroid aplasia or in situ gland attained a similar mean final height (0.1 \pm 1.1 SDS, $0.5 \pm 1.0$ SDS and $-0.5 \pm 1.0$ SDS, respectively), which was in all cases greater than target height $(-1.0 \pm 0.9,-0.6 \pm 0.8,-0.9 \pm 0.8$ respectively; $P<0.05)$.

Conclusions: Our results suggest that conventional management of children with $\mathrm{CH}$ detected by neonatal screening leads to normal sexual development and normal adult height, and that the major factor determining height in these children is familial genetic growth potential.
\end{abstract}

European Journal of Endocrinology 145 377-383

\section{Introduction}

Thyroid hormones are essential for normal growth and brain development. Although the introduction of systematic neonatal screening for congenital hypothyroidism $(\mathrm{CH})$ has prevented brain damage, subtle neurological dysfunctions or subnormal intelligence quotients, despite early diagnosis and treatment, have been reported in some cases (1-4). It is generally accepted that the degree of hypothyroidism at diagnosis, the timing of the onset of treatment and the doses of replacement $\mathrm{L}$-thyroxine $\left(\mathrm{L}-\mathrm{T}_{4}\right)$ are the major determinants of intellectual outcome (5-8).

Whether these factors may affect also linear growth in children with $\mathrm{CH}$, detected by screening and treated from early infancy, remains controversial. Several studies have in fact reported a normal linear growth in infancy and childhood (9-11), whereas others found a slightly deviant growth in the first years of life in children with severe $\mathrm{CH}$ at diagnosis $(12-14)$. Recent data on final height in patients with $\mathrm{CH}$, detected by neonatal screening, suggest that the amount of replacement $\mathrm{L}_{\mathrm{T}} \mathrm{T}_{4}$ received in the first 6 months of life may strongly influence the attainment of normal adult height (15).

The aim of the present study was to evaluate retrospectively the longitudinal growth, pubertal development and final height in patients with $\mathrm{CH}$ detected by neonatal screening and to identify factors potentially affecting growth outcome. 


\section{Patients and methods}

Of the 60 children referred to our department between 1981 and 1984 by the regional screening programme for congenital hypothyroidism, five were lost to followup. The remaining 55 patients (41 females) were followed longitudinally from the time of diagnosis until they reached their final height. The diagnosis was confirmed by serum thyroid function tests. Therapy with $\mathrm{L}-\mathrm{T}_{4}$ was begun immediately after the first evaluation, at a mean chronological age of $25 \pm 5$ days (range 11-31 days), at an initial dose of $25 \mu \mathrm{g}$, given orally once a day, which represented a mean of $7.0 \pm 1.8 \mu \mathrm{g} / \mathrm{kg}$ body weight. Initial $\mathrm{L}-\mathrm{T}_{4}$ dosage was modified during follow-up according to clinical and biochemical observations in an attempt to keep serum $\mathrm{T}_{4}$ and free $\mathrm{T}_{4}$ concentrations in the upper normal range and serum thyroid-stimulating hormone (TSH) in the normal range. Children were evaluated at the ages of 3, 6, 9 and 12 months of life, then every 3 or 6 months until the age of 3 years, and annually thereafter.

The aetiological diagnosis of $\mathrm{CH}$ was performed by ${ }^{99 \mathrm{~m}}$ Tc-pertechnetate or iodine-123 thyroid scans, either at the time of diagnosis or at the age of 3 years after the withdrawal of $\mathrm{L}-\mathrm{T}_{4}$ therapy for 6 weeks. Twenty-five children were classified as having ectopic glands, 10 had thyroid aplasia and 11 showed an in situ gland.

Skeletal maturity was assessed annually using the atlas of Greulich \& Pyle (16) and predicted adult height was estimated by the method of Bayley \& Pinneau (17).

Supine length until 2 years of age and standing height thereafter were measured using a Harpenden stadiometer and expressed as standard deviation score (SDS) for chronological age according to Tanner et al. (18). British growth standards were chosen because they proved to be similar to our regional percentiles (19). Final height, evaluated at a mean age of $16.5 \pm$ 0.5 years in females and $17.5 \pm 0.5$ years in males, was defined as a growth velocity of less than $1 \mathrm{~cm}$ in the preceding year. Parental height was measured at referral and SDS of the genetic target height (sexcorrected mid-parental height) was calculated according to Tanner et al. (18). Final height was also expressed as the percentage of target height achieved by the patients.

The increase in weight was expressed as body mass index (BMI), calculated by dividing weight in kilograms by the square of the height (20), and was compared with reference percentiles according to Must et al. (21).

The onset of puberty was defined by the beginning of breast development (B2) in girls and the enlargement of testicular volume to $4 \mathrm{ml}(\mathrm{G} 2)$ in boys. Pubertal growth was evaluated using the total pubertal height gain from the onset of puberty to final height (22).

\section{Statistical analysis}

Statistical analysis was performed using the Student's $t$-test or Mann-Whitney rank sum test as appropriate, and linear regression analysis. A $P$ value $<0.05$ was considered statistically significant. Results are reported as mean \pm S.D.

\section{Results}

Main clinical data on pubertal development and final height for both boys and girls are reported in Table 1 . The onset of puberty occurred at normal ages in both males and females; menarche, in females, occurred at a mean age of $12.5 \pm 1.2$ years, which was similar to the age observed in a regional control group of 50 healthy young girls $(12.5 \pm 1.0$ years). Mean total pubertal growth was normal in boys $(28.2 \pm 5.5 \mathrm{~cm})$ and slightly decreased in girls $(21.4 \pm 5.5 \mathrm{~cm})$ compared with mean values reported by Tanner $(28 \mathrm{~cm}$ in boys and $25 \mathrm{~cm}$ in girls) (23). Nevertheless, both males and females attained a mean adult height within the normal range for the reference population and above the target height $(P=0.02)$ (Fig. 1). Final height was positively correlated with target height $(r=0.80, P<0.0001)$, with predicted adult height at 7 years of age $(r=0.90$, $P<0.0001)$ and with height both at onset of puberty $(r=0.72, P<0.0001)$ and at menarche $(r=0.91$, $P<0.0001)$.

Figure 2 shows the longitudinal increase in length/ height and BMI in boys and girls. The linear growth (Fig. 2A) progressed similarly in males and females through infancy and childhood. In both sexes BMI (Fig. 2B) was above the 95th percentile until 6 years of age (greater than the reference population for sex and age) and ranged between the 50th and the 85th percentile in the subsequent years.

Bone age maturation (Fig. 2C) was delayed in the first years of follow-up compared with chronological age; however, by the age of 5 years the bone age/ chronological age ratio was 1 for both boys and girls,

Table 1 Major clinical features of the 55 patients with $\mathrm{CH}$ detected by neonatal screening and treated within the first month of life.

\begin{tabular}{lcr}
\hline & $\begin{array}{c}\text { Boys } \\
(n=14)\end{array}$ & $\begin{array}{c}\text { Girls } \\
(n=41)\end{array}$ \\
\hline Chronological age at diagnosis (days) & $26 \pm 4$ & $25 \pm 6$ \\
Serum $\mathrm{T}_{4}$ at diagnosis $(\mu \mathrm{g} / \mathrm{dl})$ & $3.8 \pm 3.2$ & $3.9 \pm 2.6$ \\
Initial L-T 4 dose $(\mu \mathrm{g} / \mathrm{kg}$ per day) & $7.2 \pm 1.8$ & $6.2 \pm 1.8$ \\
Age at onset of puberty (years) & $11.3 \pm 1.0$ & $10.3 \pm 1.2$ \\
Age at onset of pubarche (years) & $11.2 \pm 1.6$ & $9.9 \pm 1.5$ \\
Age at menarche (years) & - & $12.5 \pm 1.2$ \\
Height at onset of puberty (cm) & $146.3 \pm 8.8$ & $140.6 \pm 7.9$ \\
Final height $(\mathrm{cm})$ & $174.5 \pm 6.6$ & $162.0 \pm 6.0$ \\
Total pubertal growth (cm) & $28.2 \pm 5.5$ & $21.4 \pm 5.5$ \\
Target height $(\mathrm{cm})$ & $169.2 \pm 4.5$ & $156.3 \pm 5.6$ \\
\% Target height & $103 \pm 2$ & $103 \pm 3$ \\
\hline
\end{tabular}




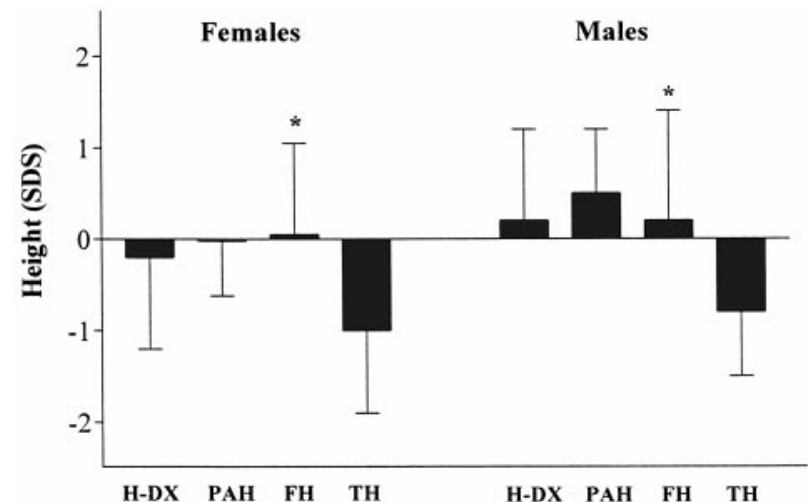

Figure 1 Height at diagnosis (H-DX), predicted adult height at 7 years of age (PAH), final height (FH) and target height $(\mathrm{TH})$ in 41 females and 14 males with $\mathrm{CH}$ detected by neonatal screening and treated within the first month of life. Values are expressed as mean \pm S.D. ${ }^{\star} P<0.02$ compared with $\mathrm{TH}$.

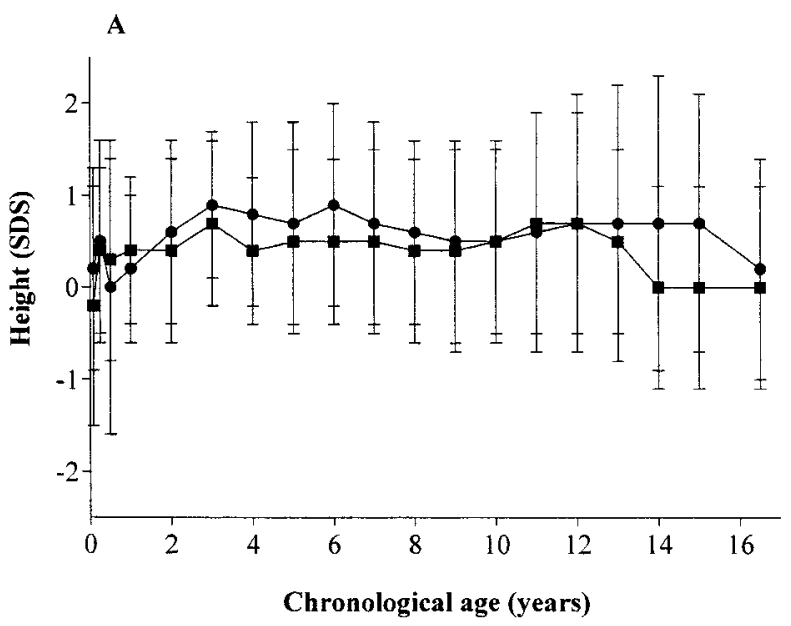

and the increase in skeletal maturation paralleled the increase in chronological age.

No significant differences were observed in longitudinal growth, pubertal development and final height between patients with different aetiologies of the defect: the longitudinal increases in length/height (Fig. 3A) and in BMI (Fig. 3B) were similar in patients with ectopic gland, thyroid aplasia and in situ gland. All patients reached adult heights that were normal according to the predicted adult height at the age of 7 years and above the genetic target $(P<0.05)$ (Fig. 4).

The onset of puberty, the age of menarche and the final height were not influenced by the severity of hypothyroidism at diagnosis. In females with severe hypothyroidism at diagnosis (serum $\mathrm{T}_{4}<3 \mu \mathrm{g} / \mathrm{dl}$ ) the onset of puberty $(10.4 \pm 1.3$ years $)$ and menarche $(12.5 \pm 1.2$ years) occurred at the same ages

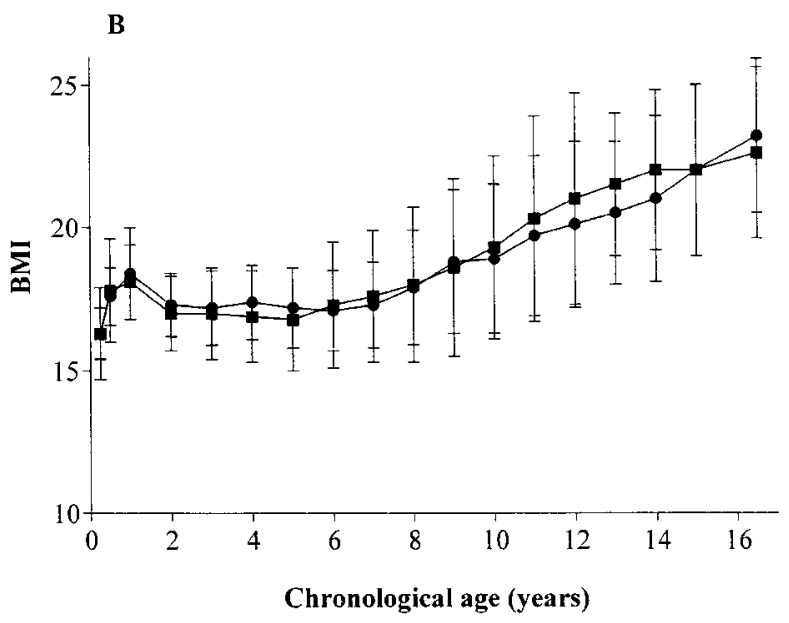

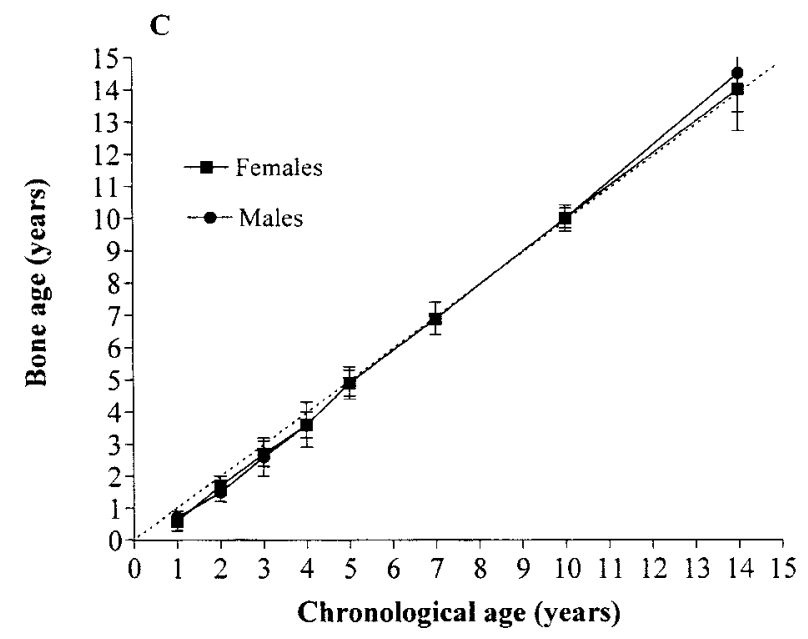

Figure 2 Longitudinal increase in length/height expressed as SDS (A), and in weight expressed as BMI (B), and skeletal maturation (C) in 41 females and 14 males with $\mathrm{CH}$ detected by neonatal screening and followed-up to adult height. Dotted line in (C) indicates the ideal bone age maturation with respect to chronological age. Values are expressed as mean \pm S.D. 
A

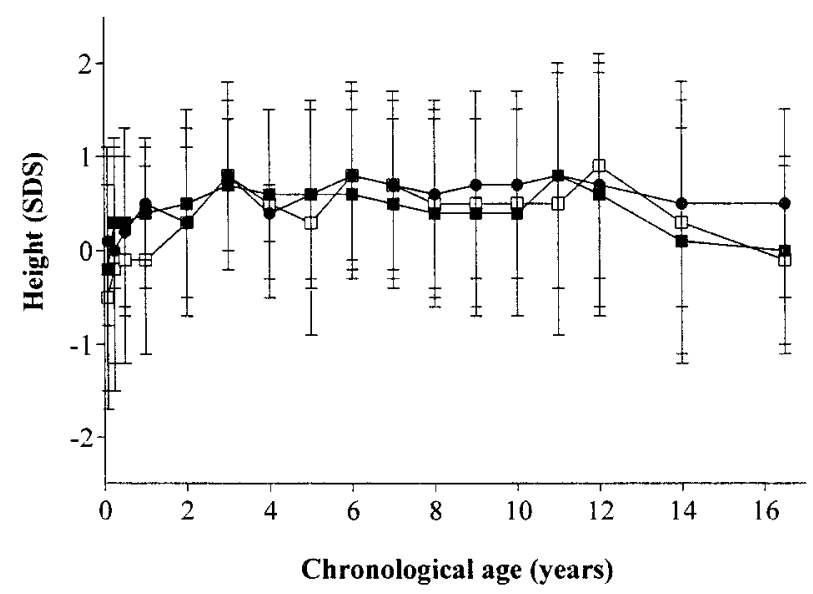

B

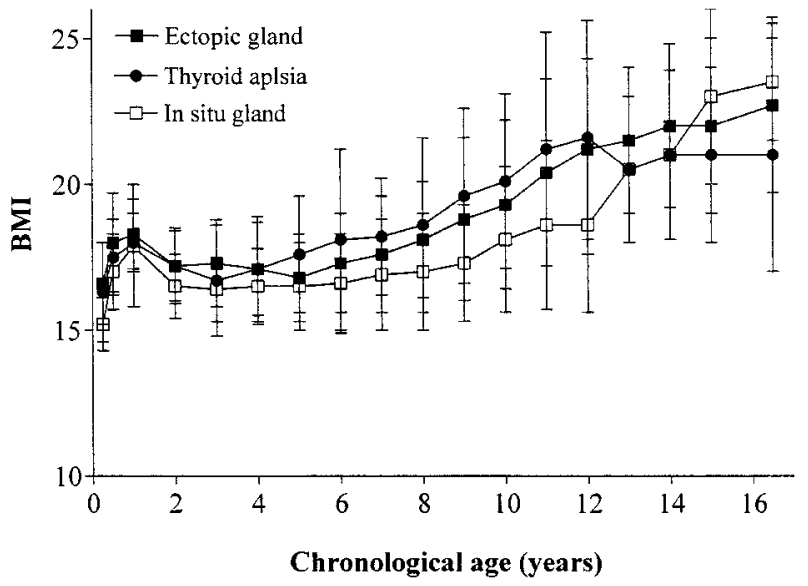

Figure 3 Longitudinal increase in length/height expressed as SDS (A), and in weight expressed as BMI (B), from the beginning of the treatment to adult height in patients with $\mathrm{CH}$ divided according to the aetiology: ectopic gland $(n=25)$, thyroid aplasia $(n=10)$ and in situ gland $(n=11)$. Values are expressed as mean \pm S.D.

$(10.1 \pm 1.2$ and $12.4 \pm 1.2$ years respectively) as in girls with moderate hypothyroidism (serum $\mathrm{T}_{4}$ $>3 \mu \mathrm{g} / \mathrm{dl}$ ). In males the onset of puberty occurred at a similar age $11.8 \pm 1.3$ years and $11.0 \pm 0.8$ years in patients with severe or moderate hypothyroidism respectively. Mean final height in all the patients (males and females) with severe $\mathrm{CH}$ did not differ from that of those with the moderate form (Fig. 5) and in both groups it was greater than target height $(P<0.0001)$.

In 11 girls treated with an initial $\mathrm{L}-\mathrm{T}_{4}$ dose greater than $8 \mu \mathrm{g} / \mathrm{kg}$ per day, puberty occurred earlier than in 30 girls treated with an initial lower amount of $\mathrm{L}^{-\mathrm{T}_{4}}$ $(<8 \mu \mathrm{g} / \mathrm{kg}$ per day); nevertheless, final height was similar in both groups (Table 2). As depicted in Fig. 6 all patients, boys and girls, attained a normal adult

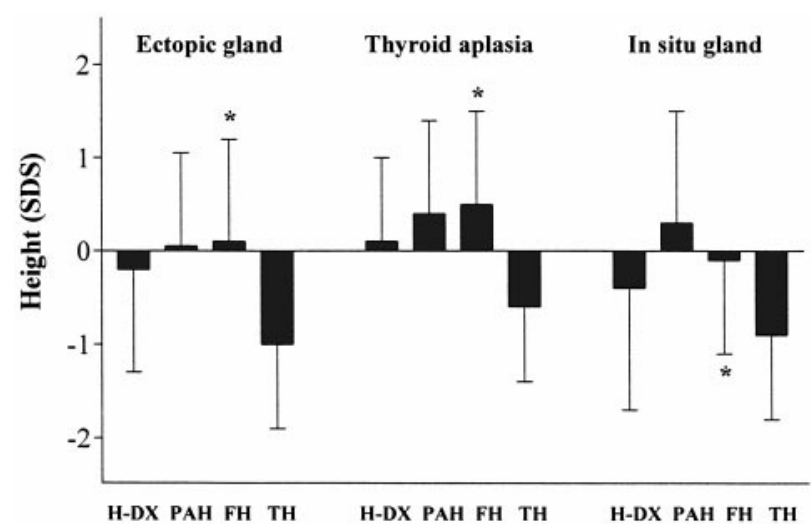

Figure 4 Height at diagnosis (H-DX), predicted adult height at 7 years of age $(\mathrm{PAH})$, final height $(\mathrm{FH})$ and target height $(\mathrm{TH})$ in patients with $\mathrm{CH}$ divided according to the aetiology: ectopic gland $(n=25)$, thyroid aplasia $(n=10)$ and in situ gland $(n=11)$. Values are expressed as mean \pm S.D. ${ }^{*} P<0.05$ compared with $\mathrm{TH}$. height significantly greater than the genetic potential $(P<0.05)$, independently of the initial amount of $\mathrm{L}-\mathrm{T}_{4}$.

In addition, no significant relationships were found between the $\mathrm{L}^{-} \mathrm{T}_{4}$ dose during the first $3-6$ or 12 months of treatment, the compliance with the treatment (evaluated by the mean serum TSH values during the first 2 years of life or during the period 2-10 years of age) and pubertal development or the final height (data not shown).

No significant differences were observed in sexual maturation and final height between patients treated before and after the first 3 weeks of life (data not shown). In order to evaluate better the impact of chronological age at the beginning of treatment on

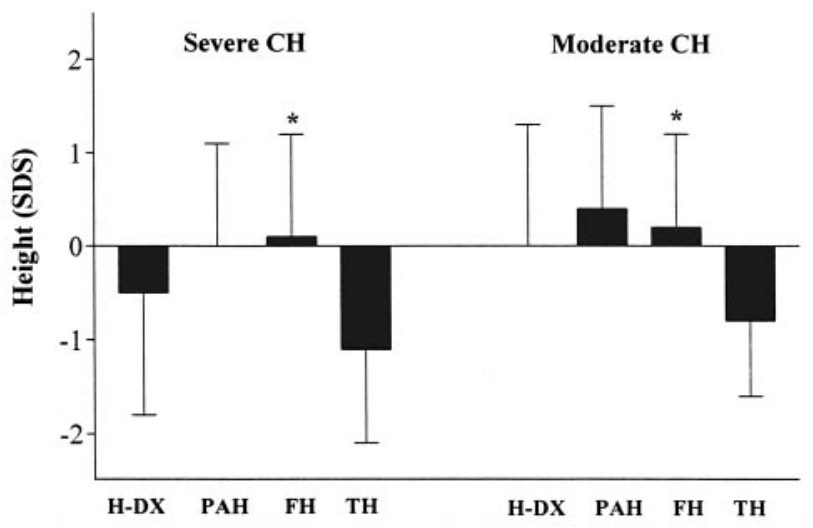

Figure 5 Height at diagnosis (H-DX), predicted adult height at 7 years of age $(\mathrm{PAH})$, final height $(\mathrm{FH})$ and target height $(\mathrm{TH})$ in 27 patients with severe $\mathrm{CH}$ at diagnosis (serum $\mathrm{T}_{4}<3 \mu \mathrm{g} / \mathrm{dl}$ ) and 28 patients with moderate $\mathrm{CH}$ at diagnosis (serum $\mathrm{T}_{4}>3 \mu \mathrm{g} / \mathrm{dl}$ ).

Values are expressed as mean \pm S.D. ${ }^{*} P<0.0001$ compared with $\mathrm{TH}$. 
Table 2 Sexual maturation and final height in 41 girls with $\mathrm{CH}$ treated with different initial replacement doses of L-T 4 .

\begin{tabular}{|c|c|c|c|}
\hline & \multicolumn{2}{|c|}{ Initial dose of $L-T_{4}$} & \multirow[b]{2}{*}{$P$} \\
\hline & $\begin{array}{c}<8 \mu \mathrm{g} / \mathrm{kg} \\
\text { per day }(n=30)\end{array}$ & $\begin{array}{c}>8 \mu \mathrm{g} / \mathrm{kg} \\
\text { per day }(n=11)\end{array}$ & \\
\hline Chronological age at diagnosis (days) & $25 \pm 5$ & $26 \pm 6$ & NS \\
\hline Serum $\mathrm{T}_{4}$ at diagnosis $(\mu \mathrm{g} / \mathrm{dl})$ & $3.8 \pm 3.5$ & $3.5 \pm 2.1$ & NS \\
\hline Initial L-T ${ }_{4}(\mu \mathrm{g} / \mathrm{kg}$ per day) & $6.3 \pm 0.9$ & $9.9 \pm 2.2$ & $<0.0001$ \\
\hline Age at onset of puberty (years) & $10.5 \pm 1.2$ & $9.4 \pm 0.9$ & $=0.02$ \\
\hline Age at onset of pubarche (years) & $10.3 \pm 1.2$ & $8.0 \pm 0.6$ & $<0.0001$ \\
\hline Age at menarche (years) & $12.6 \pm 1.2$ & $11.5 \pm 0.8$ & $=0.01$ \\
\hline Final height (SDS) & $-0.1 \pm 1.0$ & $0.4 \pm 1.0$ & NS \\
\hline$\%$ Target height & $104 \pm 3$ & $103 \pm 4$ & NS \\
\hline
\end{tabular}

pubertal development and final height, data from the patients in the study were compared with those from 46 patients with $\mathrm{CH}$ diagnosed, in our department, before the introduction of neonatal screening. Despite the late diagnosis and treatment $(8.0 \pm 7.0$ months) and the low amount of initial $\mathrm{L}-\mathrm{T}_{4}$ administered $(4.9 \pm 2.5 \mu \mathrm{g} / \mathrm{kg}$ per day), patients showed a normal sexual maturation and reached a mean adult height $(-0.4 \pm 0.8$ SDS $)$ above their target height $(-1.0 \pm 0.9$ SDS; $P=0.001)$. However, height at diagnosis and final height were significantly shorter compared with those of patients detected earlier by neonatal screening $(P<0.02)$, despite a similar target height (Fig. 7).

\section{Discussion}

There is no doubt that linear growth, pubertal development and final height are normal in children with $\mathrm{CH}$ treated from the first weeks of life. Several data have been reported on linear growth during infancy and childhood. However, whereas some authors report a normal linear growth (9-11), others provide

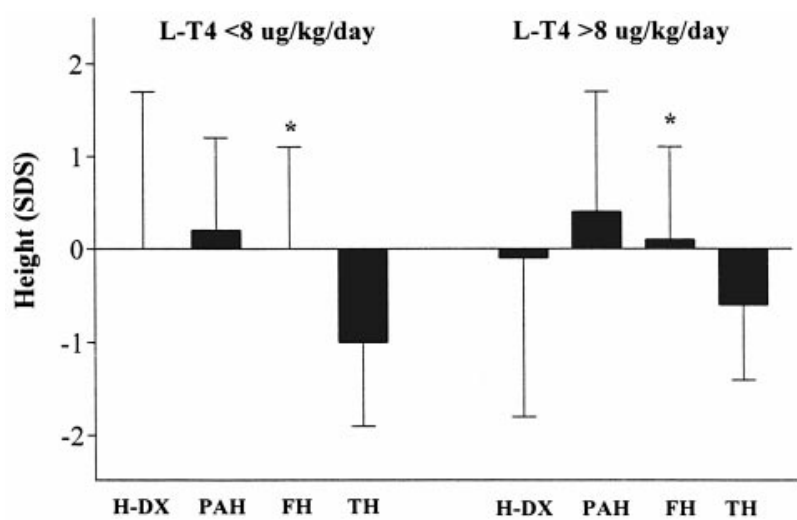

Figure 6 Height at diagnosis (H-DX), predicted adult height at 7 years of age (PAH), final height $(\mathrm{FH})$ and target height $(\mathrm{TH})$ in 40 patients treated with a lower initial amount of $\mathrm{L}^{\mathrm{T}} \mathrm{T}_{4}(<8 \mu \mathrm{g} / \mathrm{kg}$ per day) and 15 patients treated with a greater initial dose of L- $\mathrm{T}_{4}$ $(>8 \mu \mathrm{g} / \mathrm{kg}$ per day). Values are expressed as mean \pm S.D. ${ }^{\star} P<0.05$ compared with $\mathrm{TH}$. evidence of a significant delay of increase in length during the first year of life in children with athyreosis (24) and in patients with more severe hypothyroidism at diagnosis $(12-14)$. The only data available on adult height, in a small group of patients with $\mathrm{CH}$ (15), indicate that a large daily dose of $\mathrm{L}-\mathrm{T}_{4}$ is necessary in the first 6 months of treatment if the child is to attain a normal adult height. Therefore the question as to whether linear growth and final height might be affected by several factors, as is the case for intellectual outcome, seems to be controversial.

Our results indicate that puberty began within a normal age span and progressed normally in boys and girls, independently of the aetiology of $\mathrm{CH}$, the severity of $\mathrm{CH}$, and the timing of the beginning of treatment. In fact patients diagnosed after the first months of life, before the introduction of neonatal screening, also showed a normal pattern of pubertal development. Although few girls initially treated with a larger amount of $\mathrm{L}_{-} \mathrm{T}_{4}$ showed an earlier

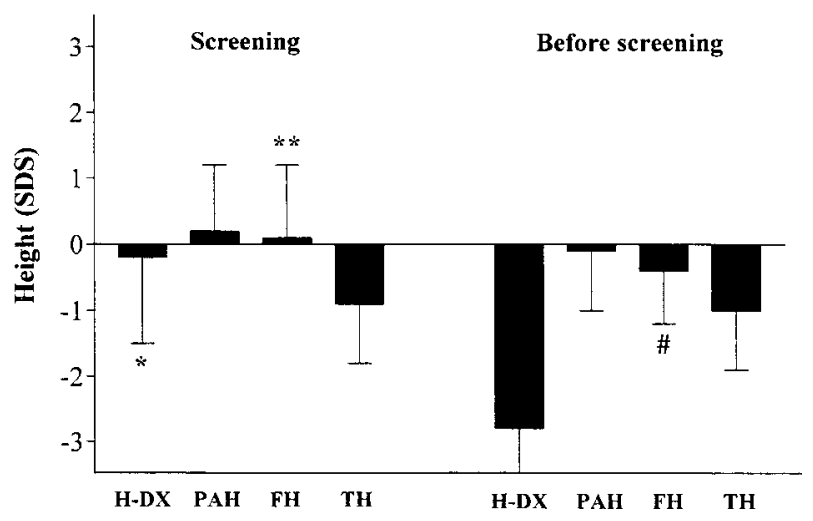

Figure 7 Height at diagnosis (H-DX), predicted adult height at 7 years of age $(\mathrm{PAH})$, final height $(\mathrm{FH})$ and target height $(\mathrm{TH})$ in 55 patients with $\mathrm{CH}$ detected by neonatal screening and treated within the first month of life and in 46 patients with $\mathrm{CH}$ diagnosed before the introduction of neonatal screening programme and treated after the first month of life. Values are expressed as mean \pm S.D. ${ }^{*} P<0.0001$ compared with patients not from screening; ${ }^{\star \star} P<0.02$ compared with patients not from screening and $P<0.0001$ compared with $\mathrm{TH}$; ${ }^{\#} P=0.001$ compared with $\mathrm{TH}$ and $P<0.0001$ compared with H-DX. 
onset of puberty, mean final height did not differ from that of girls treated with a lower starting dose of $\mathrm{L}-\mathrm{T}_{4}$.

All patients in the study attained a mean final height within the normal range for the reference population and above the target height. We did not find any relationship between final height and severity of $\mathrm{CH}$ at diagnosis, $\mathrm{L}_{-} \mathrm{T}_{4}$ dosage at beginning of treatment, or aetiology of the defect. Patients with a more severe hypothyroidism at diagnosis and those with thyroid aplasia reached a mean final height that was not significantly different from that of the other group and in all cases it was greater than their genetic target. In patients treated within the first month of life, no significant differences were observed either in height at the beginning of treatment or in final height comparing patients treated before or after the first 3 weeks of life. However, the delay in treatment in patients diagnosed before the introduction of systematic neonatal screening resulted in a severely short stature at the beginning of treatment and a mean adult height significantly shorter than that achieved by patients detected by neonatal screening.

Patients with $\mathrm{CH}$ were heavier than the reference population, not only in the first years of life (12), but also during childhood and adolescence. However, the increase in weight was not correlated with any one of the factors just considered for the linear growth. The overweight status observed in several patients with $\mathrm{CH}$ deserves further attention as, far from being related to a condition of under-treatment, it might be the result of an incorrect parent-child affective relationship finally results in an overfeeding of child and adolescent (4).

Our results, in agreement with those of Dickerman \& De Vries (15), indicate that patients with $\mathrm{CH}$ have a normal sexual maturation and attain a normal adult height; however, we did not observe any relationship between final height and $\mathrm{L}^{-} \mathrm{T}_{4}$ dosage, either at the beginning or during the first year of treatment. Moreover, we have recently demonstrated that greater initial doses of $\mathrm{L}^{-} \mathrm{T}_{4}$ do not improve linear growth in the first 4 years of age, the growth pattern for height and weight being similar in the low-dose treated and the high-dose treated patients (25).

In conclusion, our results suggest that conventional management of children with $\mathrm{CH}$ detected by neonatal screening leads to normal sexual development and normal adult height, and that the major factor determining height in these children is familial genetic growth potential.

\section{Acknowledgements}

This work was presented in abstract form at the 39th Annual Meeting of the European Society for Paediatric Endocrinology, Brussels 17-19 September 2000.

\section{References}

1 Fuggle PW, Grant DB, Smith I \& Murphy G. Intelligence, motor skills and behavior at 5 years in early-treated congenital hypothyroidism. European Journal of Pediatrics $1991 \quad 150$ 570-574.

2 Glorieux J, Dussault J \& Van Vliet G. Intellectual development at age 12 years of children with congenital hypothyroidism diagnosed by neonatal screening. Journal of Pediatrics 1992 $121581-584$.

3 Kooistra L, Laane C, Vulsna T, Schellekens JM, Van der Meere JJ \& Kalverboer AF. Motor and cognitive development in children with congenital hypothyroidism: a long-term evaluation of the effects of neonatal treatment. Journal of Pediatrics 199424 903-909.

4 Salerno M, Militerni R, Di Maio S, Bravaccio C, Gasparini N \& Tenore A. Intellectual outcome at 12 years of age in congenital hypothyroidism. European Journal of Endocrinology 1999141 105-110.

5 Derksen-Lubsen G \& Verkerk PH. Neuropsychologic development in early treated congenital hypothyroidism: analysis of literature data. Pediatrics Research 199639 561-566.

6 Salerno M, Di Maio S, Militerni R, Argenziano A, Valerio G \& Tenore A. Prognostic factors in the intellectual development at 7 years of age in children with congenital hypothyroidism. Journal of Endocrinological Investigation 199518 774-779.

7 Heyerdahl S, Kase BF \& Lie SO. Intellectual development in children with congenital hypothyroidism in relation to recommended thyroxine treatment. Journal of Pediatrics $1991 \mathbf{1 1 8}$ $850-857$.

8 Bongers-Schokking JJ, Koot HM, Wiersma D, Verkerk PH \& de Muinck Keizer-Shrama SMPF. Influence of timing and dose of thyroid hormone replacement on development in infants with congenital hypothyroidism. Journal of Pediatrics 2000136 292-297.

9 Bucher H, Prader A \& Illig R. Head circumference, height, bone age and weight in 103 children with congenital hypothyroidism before and during thyroid hormone replacement. Helvetica Paediatrica Acta 198540 305-316.

10 Moschini P, Costa P, Marinelli E, Maggioni G, Sorcini Carta M, Fazzini $\mathrm{C}$ et al. Longitudinal assessment of children with congenital hypothyroidism detected by neonatal screening. Helvetica Paediatrica Acta 198641 415-424.

11 Moreno L, Ythier H, Loeuille GA, Lebeq MF, Dhondt JL \& Farriaux JP. Etude de la croissance et de la maturation osseuse au cours de l'hypotyroidie congenitale depistée en période néonatale. A propos de 82 observations. Archives Françaises de Pédiatrie 198946 723-728.

12 Grant DB. Growth in early treated congenital hypothyroidism. Archives of Disease in Childhood 199470 464-468.

13 Aronson R, Ehrlich RM, Bailey JD \& Rovet JF. Growth in children with congenital hypothyroidism detected by neonatal screening. Journal of Pediatrics 1990116 33-37.

14 Heyerdahl S, Ilicki A, Kalberg J, Kase BF \& Larsson A. Linear growth in early treated children with congenital hypothyroidism. Acta Paediatrica 199786 479-483.

15 Dickerman Z \& De Vries L. Prepubertal and pubertal growth, timing and duration of puberty and attained adult height in patients with congenital hypothyroidism $(\mathrm{CH})$ detected by the neonatal screening program for $\mathrm{CH}$ - a longitudinal study. Clinical Endocrinology 199747 649-654.

16 Greulich WW \& Pyle SI. Radiographic Atlas of Skeletal Development of the Hand and Wrist, 2nd edn. Stanford: Stanford University Press, 1952.

17 Bayley N \& Pinneau SR. Tables for predicting adult height from skeletal age: revised for use with the Greulich and Pyle hand standard. Journal of Pediatrics $1952 \mathbf{4 0} 423-441$.

18 Tanner JM, Whitehosue RH \& Takaishi M. Standards from birth to maturity for height, weight, height velocity and weight velocity: British children 1965. Archives of Disease in Childhood $196641613-635$. 
19 Capozzi G, Vitiello N, Granato L, Gargiulo ML, Langella S \& Greco L. Factors related to growth in height: are regional standards still required? Italian Journal of Pediatrics $1988 \mathbf{1 4}$ 384-389.

20 Poskitt EME. Defining childhood obesity: the relative body mass index (BMI). Acta Paediatrica 199584 961-963.

21 Must A, Dallal GE \& Dietz WH. References data for obesity: 85th and 95th percentiles of body mass index $\left(\mathrm{W} / \mathrm{H}^{2}\right)-$ a correction. American Journal of Clinical Nutrition $1991 \mathbf{5 4}$ 773.

22 Bourguignon JP. Linear growth as a function of age at onset of puberty and sex steroids dosage: therapeutic implications. Endocrine Review 19889 467-488.

23 Tanner JM. In Growth at Adolescence, 2nd edn. Oxford, UK: Blackwell Scientific, 1962.
24 Siragusa V, Terenghi A, Rondanini GF, Vigone MC, Galli L Weber $\mathrm{G}$ et al. Congenital hypothyroidism: auxological retrospective study during the first six years of age. Journal of Endocrinological Investigation 199619 224-229.

25 Salerno M, Di Maio S, Micillo M, Officioso A, Ferri P, Lettiero T et al. Effect of different starting doses of L-thyroxine on intellectual outcome in congenital hypothyroidism. Hormone Research 200053 (Suppl 2) 116.

Received 26 January 2001

Accepted 4 May 2001 